\title{
PIEDAD POPULAR Y DÍA DEL SEÑOR: ¿CERCANOS O DISTANTES? Perspectiva sociológica
}

DOI: https://doi.org/10.52039/seminarios.v65i226.25

JAVIER ELZO IMAZ*

\section{INTRODUCCIÓN}

En estas páginas vamos a reflexionar, desde una perspectiva sociológica, sobre la realidad en nuestros días de la práctica dominical, por un lado, y de la asistencia a determinados lugares de signo religioso, por otro.

La percepción común es que se está produciendo un descenso en la participación en la misa dominical -idea que los datos confirman- mientras que se mantiene e incluso aumenta la visita a ciertos espacios de piedad popular que, en muchos casos, no conllevan la asistencia a la eucaristía. Sin embargo, aquí hay que trabajar con más cuidado. Tenemos información suficiente, aunque muy elemental, sobre la práctica dominical, pero sobre la denominada piedad popular la investigación científica es muy escasa y por lo general se asemeja, en gran medida, a estudios de casos.

En este artículo nos fijaremos en tres manifestaciones de piedad popular: el Camino de Santiago, la Semana Santa de Priego (Córdoba) y el santuario de la Virgen de Lourdes. La selección de estos espacios de piedad popular responde, sobre todo, al hecho de que hemos encontrado información científica, o asimilable, sobre los tres. Nos serviremos también de las conclusiones de un Congreso sobre Religiosidad popular que se celebró en Padua en octubre de 2012.

\section{SOBRE EL DíA dEL SEÑOR}

\section{La asistencia a la iglesia como indicador de religiosidad}

La frecuencia con que se asiste a la iglesia ha sido tradicionalmente un indicador muy valioso a la hora de determinar el grado de religiosidad de los

* Francisco Javier Elzo Imaz es Catedrático emérito de Sociología en la Universidad de Deusto. 
fieles. Sin embargo, hubo momentos en los que no era o no se consideraba un dato fiable, y también hoy es cuestionado como indicador válido de religiosidad. En el ya lejano Informe de la Fundación Santa María sobre los jóvenes de $1989^{1}$, señalábamos que la asistencia a misa había sido puesta en duda como indicador válido de la religiosidad de una comunidad o un colectivo y que seguía cuestionada por muchos sociólogos en aquel momento. En los años anteriores al Concilio, porque dominaba el «estado de cristiandad» y había una cierta coacción social para ir a misa, especialmente en las poblaciones pequeñas y medianas, donde la presión social tenía más fuerza. Esto ponía en duda la validez del indicador como prescriptor de religiosidad.

Sin embargo, después del Concilio sucede algo inesperado, que con toda rotundidad cabe denominar el derrumbe de la práctica religiosa en gran parte de Europa occidental de matriz católica, particularmente en Francia, a la que seguiría pocos años después España. Estábamos en la década de 1960, que constituye -según algunos autores, entre los que me incluyo- un periodo clave, un periodo de mutación cultural. Así lo afirma Olivier Roy en una publicación de 2019 al titular su capítulo 5 así: «La ruptura antropológica de los años 1960» y el siguiente: "Secesión religiosa: la encíclica Humanae vitae (julio de 1968) $»^{2}$. En efecto, después del Concilio Vaticano II cabe mencionar, entre otras cosas, la decisión de Pablo VI de publicar en julio de 1968, en contra de la opinión mayoritaria de la comisión que él mismo había formado, la encíclica Humanae vitae, que defiende una posición maximalista que prohíbe cualquier práctica sexual no destinada a la procreación, cosa que una gran mayoría de laicos (y no pocos clérigos y teólogos) no pueden entender y que, de hecho, no acatan. Pero hay más.

Escribíamos en el Informe de 1989 ya mentado que era fácil encontrar expresiones como estas: «Muchos van a misa solo para que los vean»; «mucho ir a misa, pero luego en su vida cotidiana es un sinvergüenza»; «yo no voy a misa, pero esto no me parece fundamental», y más claramente: "Se puede ser buen cristiano sin ir a misa», etc., que eran moneda corriente en los años setenta, incluso entre quienes se autodenominaban católicos (p. 256). Es la autosecularización de lo religioso, que se manifiesta claramente en la práctica dominical, pero también en las creencias religiosas y en otras prácticas tan centrales como bodas, bautismos, etc.

De hecho, tras el Vaticano II se extiende en la propia Iglesia, en muchos teólogos e incluso en sacerdotes una infravaloración de la práctica religiosa

1. J. Elzo, Actitudes de los jóvenes españoles frente al tema religioso, en P. González Blasco (dir.), Jóvenes Españoles 89, Fundación Santa María - Ediciones SM, Madrid 1989, 253-334.

2. O. Roy, L'Europe est elle chretien?, Seuil, Paris 2019, 87ss. 
y de la dimensión cultual de la fe. De entrada, la misa y la confesión: para ser un buen cristiano no hace falta ir a misa, ni pasar por el confesonario ${ }^{3}$. Después, de forma sorpresiva, imprevista y creciente, caen los matrimonios religiosos y los bautizos. El último bastión que, en algunas partes -como en el País Vasco-, ya se está viniendo abajo son los funerales.

A todo lo anterior, y no solo entre los jóvenes, hay que añadir otro fenómeno: el cambio en las formas de usar el tiempo libre, sea en las salidas nocturnas de los viernes y sábados -que, como es obvio, tenían una fuerte incidencia en sus posibilidades de asistir a la misa dominical-, o en los desplazamientos de fines de semana. Ir a misa ha dejado de formar parte del universo mental de la gente, incluso de los que se dicen católicos. Nada que ver con aquellas misas que se celebraban a las cinco y media de la madrugada en la estación de San Sebastián o en cierto local religioso adscrito a una empresa de mi localidad natal, Beasain, para que los montañeros (y los cazadores en otoño) «cumplieran con el precepto dominical». Todo esto ha desaparecido completamente.

Además, el «finde» ya ha adquirido carta de naturaleza en España. A lo que hay que añadir lo que señalábamos con fuerza en la Encuesta Europea de Valores aplicada a España el año 20004: el imparable aumento del individualismo y el drástico declive del sentimiento de colectividad (exceptuando el sentimiento de pertenencia, rayano en el populismo) no solo dentro de la Iglesia, sino también en la sociedad civil cuando de valores colectivos de cierta amplitud se trata. En realidad, estamos ante un proceso que ha ido in crescendo hasta nuestros días. Es lo que denomino, con un oxímoron, «individualismo grupal». Esta tendencia quedó confirmada, si falta hacía, por la última Encuesta Europea de Valores publicada hasta ahora en España, que titulamos precisamente «Un individualismo placentero y protegido» ${ }^{5}$.

La asistencia a la iglesia es un acto en el que no solo hay que tener en cuenta la dimensión religiosa de la persona, sino también la dimensión comunitaria, al ser una expresión del «nosotros, la Iglesia, nos reunimos ante Ti». Pero ese «nosotros» puede ser un colectivo con determinadas connotaciones. Desde hace años, la expresión que originalmente usó Grace Davie para la deserción de la práctica religiosa compartida en Gran Bretaña, believing without belonging («creer sin pertenecer»), se ha extendido cla-

3. Un trabajo excelente sobre este tema es el de G. Cuchet, Comment notre monde a cessé d'être chrétien. Anatomie d'un effondrement, Seuil, Paris 2018.

4. F. Andrés Orizo - J. Elzo (dirs.), España 2000, entre el localismo y la globalidad. La Encuesta Europea de Valores en su tercera aplicación, 1981-1999, Universidad de Deusto Ediciones SM, Madrid 2000.

5. J. Elzo - M. Silvestre (dirs.), Un individualismo placentero y protegido. Cuarta Encuesta Europea de valores en su aplicación a España, Universidad de Deusto, Bilbao 2010. 
ramente a muchas otras áreas, entre ellas España, como han comprobado los últimos informes de la Fundación SM sobre los jóvenes y las Encuestas Europeas de Valores, en los que se pone de relieve que la religión se ve cada vez más como algo personal y privado, que no ha de tener necesariamente proyección social.

En la Encuesta Europea de Valores de 2008-2010 aplicada a España arriba referenciada, se preguntaba a una muestra representativa de españoles mayores de edad por su asistencia a la iglesia, y se puso de manifiesto que apenas el $14 \%$ acudía semanalmente. También se les pedía que indicaran la frecuencia con que asistían cuando tenían doce años, y el $45 \%$ respondió que semanal. Es evidente, pues, el gran descenso de la práctica religiosa semanal (ir a misa) en el conjunto poblacional español, básicamente adultos en dicha encuesta. Veámoslo.

\section{Evolución de la práctica religiosa en España en los últimos 35 años}

Detengámonos brevemente en los datos que nos ofrecen las encuestas del CIS desde 1984 hasta 2019, o sea, los últimos 35 años.

Evolución de la práctica religiosa en España (2019-1984)

\begin{tabular}{|l|c|c|c|c|c|c|}
\cline { 2 - 7 } \multicolumn{1}{c|}{} & $\begin{array}{c}\text { Junio } \\
1984^{*}\end{array}$ & $\begin{array}{c}\text { Octubre } \\
1994\end{array}$ & $\begin{array}{c}\text { Marzo } \\
2000\end{array}$ & $\begin{array}{c}\text { Junio } \\
2006\end{array}$ & $\begin{array}{c}\text { Mayo } \\
2014\end{array}$ & $\begin{array}{c}\text { Junio } \\
2019\end{array}$ \\
\hline Nunca / Casi nunca & 28,4 & 32,1 & 40,3 & 51,7 & 60,3 & 59,3 \\
\hline Varias veces al año & 22,4 & 23,4 & 21,5 & 18,3 & 14,5 & 17,0 \\
\hline Alguna vez al mes & 11,6 & 13,7 & 13,5 & 10,5 & 9,3 & 7,0 \\
\hline $\begin{array}{l}\text { Casi todos los do- } \\
\text { mingos y festivos }\end{array}$ & 14,8 & 25,5 & 21,1 & 15,4 & 13,3 & 12,4 \\
\hline $\begin{array}{l}\text { Todos los domingos } \\
\text { y festivos }\end{array}$ & 17,6 & - & - & - & - & - \\
\hline $\begin{array}{l}\text { Varias veces a la } \\
\text { semana }\end{array}$ & 1,7 & 4,9 & 2,9 & 2,7 & 1,7 & 1,7 \\
\hline N.C. & 3,3 & 0,5 & 0,7 & 1,3 & 0,8 & 2,5 \\
\hline (N) & 1183 & 2243 & 2122 & 1954 & 2471 & 2133 \\
\hline
\end{tabular}

Los datos son suficientemente elocuentes y no precisan comentarios. La práctica religiosa regular, «todos» y "casi todos los domingos y festivos» y «más de una vez a la semana», se cifraban en el $34 \%$ de la población el

* Son porcentajes sobre el total de españoles en 1984. Pero desde 1994, el CIS los calcula sobre el total de los que previamente se han declarado creyentes, que en su inmensa mayoría son católicos. 
año 1984. Un tercio de los españoles de más de 18 años acudían los domingos a misa hace 35 años. En la actualidad -junio de 2019-, la cifra es del $14 \%$ entre los que se dicen católicos, que se queda en el $10 \%$, como veremos más abajo, no en referencia al conjunto de los españoles, sean o no creyentes. La tabla nos muestra el continuado descenso de la práctica regular en los últimos 35 años. Al mismo tiempo, la inasistencia habitual, esto es, no ir a misa «nunca o casi nunca» (recuérdese que se exceptúan bautismos, bodas y funerales), aumenta del $28 \%$ en 1984 (en el total poblacional), pasando por el $32 \%$ entre solo los católicos en 1994, hasta el $59 \%$ (contabilizados únicamente los católicos) el año 2019.

Pero debemos subrayar asimismo que la práctica esporádica o circunstancial, "varias veces al año» y "alguna vez al mes», también ha disminuido, pasando del $37 \%$ el año 1994 (solo entre los creyentes) al $24 \%$ en 2019. Esto significa que, incluso limitándonos a la asistencia a misa en determinadas circunstancias, como Navidad, Semana Santa y algunas festividades concretas, o con ocasión de una romería, peregrinación, año santo, visita a un monasterio, fiesta local, reunión de grupos religiosos, etc. (como formulamos en las encuestas a los jóvenes, que mostraremos más adelante), también ha disminuido la asistencia a misa. Con estos datos cabe formular una hipótesis importante para el presente trabajo: que el aumento -allí donde se da- de la asistencia de la población católica a lugares de peregrinación, encuentros con cierta significación religiosa (romerías, visitas a monasterios, procesiones, encuentros de grupos de cariz religioso, etc.) no conlleva necesariamente participar en una eucaristía.

Para ser completos, y dada su relevancia social, mirando al futuro, presentamos la evolución de la asistencia a la iglesia entre los jóvenes, basada en el último trabajo de la Fundación Santa María.

Asistencia a la iglesia (1984-2016)

\begin{tabular}{|l|c|c|c|c|c|c|c|}
\cline { 2 - 8 } \multicolumn{1}{l|}{} & $\begin{array}{c}1984 \\
(3254)\end{array}$ & $\begin{array}{c}1989 \\
(4548)\end{array}$ & $\begin{array}{c}1994 \\
(2024)\end{array}$ & $\begin{array}{c}1999 \\
(3850)\end{array}$ & $\begin{array}{c}2005 \\
(4000)\end{array}$ & $\begin{array}{c}2010 \\
(3513)\end{array}$ & $\begin{array}{c}2016 \\
(954)\end{array}$ \\
\hline Más de una vez a la semana & & & 2 & 1 & 1 & 2,3 & 1,3 \\
\hline Una vez a la semana & 17 & 18 & 15 & 11 & 4 & 6,8 & 6,9 \\
\hline Una vez al mes & 9 & 9 & 9 & 9 & 5 & 5,1 & 4,8 \\
\hline $\begin{array}{l}\text { En Navidad / Semana Santa y } \\
\text { festividades concretas }\end{array}$ & 6 & 6 & 16 & 14 & 10 & 10,5 & 7,4 \\
\hline $\begin{array}{l}\text { Con ocasión de una romería, } \\
\text { peregrinación, año santo, visi- } \\
\text { ta a monasterios, fiestas loca- } \\
\text { les, etc. }\end{array}$ & & & 12 & 10 & 9 & 6,9 & 2 \\
\hline
\end{tabular}




\begin{tabular}{|l|c|c|c|c|c|c|c|}
\hline $\begin{array}{l}\text { Con ocasión de reuniones de } \\
\text { grupos religiosos }\end{array}$ & - & - & - & - & - & 1,3 & 0,6 \\
\hline $\begin{array}{l}\text { En ocasiones comprometidas } \\
\text { (exámenes, enfermedad, bús- } \\
\text { queda de trabajo, problemas } \\
\text { afectivos, etc.) }\end{array}$ & - & - & 5 & 8 & 5 & 2,2 & 0,8 \\
\hline Nunca / casi nunca & 47 & 40 & 50 & 53 & 69 & 61,8 & 78,1 \\
\hline
\end{tabular}

J. M. a González-Anleo - J. A. López-Ruiz, Jóvenes españoles entre dos siglos (19842017), Fundación Santa María, 2018.

Se constata que, entre 1984 y 2005 , la práctica regular y semanal cae del 17 al $5 \%$, creciendo mínimamente la práctica puntual en Navidad, Semana Santa o festividades concretas, aunque incluso en estas fechas caen a partir de 1994. El declive se acelera entre 1994 y 2005. En esos años la práctica semanal desciende del 12 al $5 \%$ de jóvenes, y la mensual, que se había mantenido estable de 1984 a 1999, cae del 9 al $5 \%$ entre 1999 y 2005.

¿Qué pasó entre 2005 y 2016, última fecha en que tenemos controlada la práctica religiosa de los jóvenes? Se acentuó la polarización hacia los extremos. Si en 2005 la práctica semanal es del $4 \%$, en 2016 roza el $7 \%$, mientras que quienes no van nunca o casi nunca a la iglesia pasan del $69 \%$ en 2005 al $78 \%$ en 2016 . Nótese también que la práctica en ocasiones comprometidas (exámenes, enfermedad, etc.) baja del $8 \%$ en 1999 a menos del $1 \%$.

En conclusión, cabe decir que la práctica religiosa semanal entre los jóvenes españoles es mínima, y sospechamos que residual en algunas regiones, aunque aquí y allá se observan indicios de crecimiento.

¿Hemos de concluir que, también en España, o en bastantes regiones españolas, estamos en el fin de la era parroquial? Podríamos inclinarnos por la respuesta afirmativa si pensamos solo en la vida parroquial tradicional. Pero hay que tener en cuenta que ya se otean en el horizonte otros modelos, todavía en fase experimental, y también que hay parroquias y parroquias.

En cualquier caso, este trabajo muestra el interés por llevar a cabo trabajos socio-religiosos de nuevo cuño, que muestren modos inéditos de religiosidad en la sociedad española, de los que por ahora poco podemos decir. Se ve lo que se extingue, pero apenas sí lo que nace. Es como un río que en su nacimiento brota escuálido, pero que, si a lo largo de su curso recoge muchos afluentes, desemboca caudaloso en el mar. Y la Iglesia católica en España, como otrora la protestante en Francia (aunque por caminos diferentes), corre el riesgo de diluirse en la España ultrasecularizada, cuando no eclesiófoba en ciertos ámbitos. Dilución que irá in crescendo por la lacra de la pederastia clerical, que aunque estadísticamente se remonta a los años sesenta, ochenta y noventa del siglo pasado, es ahora cuando tiene un incontenible eco 
mediático ${ }^{6}$. De todos modos, a nuestro juicio el tema central es otro, a saber: cómo se está realizando el tránsito desde la era de la cristiandad hacia la era secular a la hora de vivir y hacer presente la fe en Jesús de Nazaret.

\section{La práctica religiosa en junio de 2019 en España}

Nos detendremos ahora con cierto detalle en el Barómetro del CIS de junio de 2019, en el que se pregunta por la asistencia a misa u otros oficios religiosos a los españoles mayores de edad.

Asistencia a misa u otros oficios, excluyendo bodas, comuniones y funerales. Datos en porcentajes

\begin{tabular}{|l|c|c|}
\cline { 2 - 3 } \multicolumn{1}{c|}{} & \begin{tabular}{c} 
Todos \\
\multicolumn{1}{c|}{}
\end{tabular} & $\begin{array}{c}\text { Solo católicos } \\
\text { los españoles } \\
\text { otras religiones }\end{array}$ \\
\hline Nunca & 22 & 31 \\
\hline Casi nunca & 21 & 29 \\
\hline Varias veces al año & 12 & 17 \\
\hline Dos o tres veces al mes & 5 & 7 \\
\hline Todos los domingos y festivos & 9 & 12 \\
\hline Varias veces a la semana & 1 & 2 \\
\hline Agnósticos indiferentes, no creyentes o ateos & 27 & 2 \\
\hline N.C & 1 & 2133 \\
\hline N $=$ & 2974 & No procede \\
\hline Total & \multicolumn{2}{c|}{$100 \%$} \\
\hline
\end{tabular}

Fuente: Barómetro del CIS, junio de 2019, elaboración propia.

6. Puedo ilustrar esto con un ejemplo personal. A finales de 2008, cierto colectivo me solicitó para llevar a cabo un estudio sobre la influencia que el Seminario de Derio, en Vizcaya, había ejercido en los seminaristas que habían vivido en él entre 1953 y 1970. Mi trabajo, "Valoración global de su estancia en el Seminario», se publicó en el volumen colectivo Historia del Seminario de Derio-Bilbao. En el recuerdo de sus protagonistas, Astintze, Bilbao 2011, 575-619. Durante la atenta lectura de los 199 cuestionarios que recibí rellenados (de 603 enviados), encontré diez reportes de abusos sexuales que reseñé en su integridad (p. 610-611). Aquel libro fue objeto de una presentación pública y luego se distribuyó y vendió en librerías. Nadie, que yo sepa, escribió ni dijo nada sobre él, hasta que, en marzo de 2019 -es decir, cuando la información ya llevaba casi diez años publicada-, alguien lo "descubrió». Desde entonces los medios me «bombardearon» hasta tal extremo que acabé agotado y decidí dejar de hacer entrevistas y artículos. Al lector interesado le sugiero una larga entrevista que me hicieron en El Correo el 9 de marzo de 2019 (http://mynmedia. mynews.es/noticies/intelligence/?dre=GCE201903092065\&tipus=pdf\&idCarpeta=938). 
La columna de la izquierda («Todos los españoles») mide la práctica religiosa basándose en el conjunto de españoles mayores de edad, 2974 personas en la encuesta del CIS. La columna de la derecha mide la proporción de católicos y creyentes de otras religiones ${ }^{7}$ (excluyendo, por tanto, a los agnósticos, indiferentes, no creyentes y ateos), que suman 2133 personas.

Retengamos estos datos: si nos atenemos al conjunto de la población española, solo el $10 \%$ asiste regularmente a misa, el $9 \%$ todos los domingos y festivos, y un $1 \%$ lo hace varios días a la semana. No asiste nunca o casi nunca el $43 \%$ de los españoles, al que hay que añadir el $27 \%$ que se declara agnóstico, indiferente, no creyente o ateo, aunque es posible, e incluso probable, que algunos de ellos asistan en ocasiones puntuales (sin contar bautizos, bodas y funerales).

Si nos limitamos a quienes se declaran católicos, las cifras son: el 12,4\% afirma acudir a la Iglesia los domingos y festivos, y el 1,7\% varios días a la semana. Sumando las dos cifras, en números redondos, el $14 \%$ de los que se manifiestan como católicos asistiría a misa regularmente, una vez a la semana o más, a tenor de los datos de junio de 2019.

Segmentados por sexo y edad, estos son los datos: acuden regularmente a misa, entre los católicos, el $11 \%$ de hombres y el $17 \%$ de mujeres. Según la edad, el $4 \%$ de los jóvenes entre 18 y 24 años, el $8 \%$ de quienes tienen entre 25 y 34 años, mismo porcentaje para los de 35 a 44 años, $9 \%$ entre los de 45 a 54 años, $8 \%$ entre los de 55 a 64 años y la cifra sube al $27 \%$ entre los de 65 años y más.

¿Qué decir? El desenganche de los más jóvenes es altísimo, se acerca a una práctica residual. Desde los 25 años hasta al menos los 65, la práctica religiosa regular entre los españoles que se dicen católicos es del $8 \%$, que se quedaría en el 6 si lo calculamos sobre el conjunto poblacional español, se declaren o no católicos. Hay que llegar a los 65 años de edad para constatar que más de un cuarto de los católicos, y algo menos de ese cuarto en la población total, asisten regularmente a misa. Aunque yo apuntaría, incluso, que habríamos de pasar de los 70 años para encontrar esa cifra de asistentes a misa.

Hace muchos años que hemos constatado que la práctica religiosa en nuestros días responde a su brusca caída a finales de los años 60 del siglo pasado, década en la cual muchos estudiosos ponen el acento para enten-

7. Pero conforman solamente el $2,2 \%$ de la población, pues la mayoría de creyentes son los que se dicen católicos, practicantes y no practicantes, y no es posible segmentarlos tal y como nos ofrece los datos el CIS, que lo hace en base a los que se han declarado católicos y creyentes de otra religión. Es la columna de la derecha de la tabla. La columna de la izquierda es elaboración mía en base a los datos del CIS. 
der lo que algunos denominan la descristianización de Europa occidental que yo concreto más: en España, Portugal, Francia, Bélgica y también, aunque las he estudiado menos, Alemania y Holanda.

Las personas que solo tienen estudios primarios o menos son las que en mayor porcentaje (casi el 20\%) asisten regularmente a misa, pero es más que probable que el factor explicativo, en este caso, no sea su nivel de estudios, sino su edad y también el sexo. En efecto, el siguiente colectivo que acude con mayor frecuencia a misa es el conformado por los que tienen estudios superiores: el $12 \%$, por delante de los que no han pasado de los estudios secundarios (11\%), siendo los que han estudiado FP claramente los que en menor proporción (un $5 \%$ ) asisten a la iglesia. En efecto, en el Estudio de Valores europeo de 2019 (EVS), en su aplicación a Francia, encontramos que, manteniendo la edad constante, quienes han salido más tarde del sistema educativo son quienes en mayor proporción son católicos practicantes $^{8}$.

La práctica religiosa es claramente mayoritaria en la clase media antigua (24\%), a continuación en los de la clase media alta y muy alta (15\%) y las nuevas clases medias (13\%), siendo los menos asiduos los obreros (en torno al $11 \%)^{9}$. En Francia, en el trabajo del EVS ya referenciado, «los dos grupos profesionales católicos que practican con mayor frecuencia son los directores, cuadros directivos y gerentes (18\% de practicantes), y las profesiones intelectuales y científicas (16\%), mientras que la tasa de práctica religiosa no es sino del $9 \%$ entre los obreros de la industria y de los transportes, sean o no cualificados».

Respecto del voto político, sobre la base de a quién se votó en las generales de abril de 2019 y limitándome, por seguridad estadística, a las cinco formaciones de ámbito estatal, y con submuestra suficiente, estos son los datos en junio de 2019: el $28 \%$ de los votantes del PP acude regularmente a misa; a continuación, los votantes de Vox (25\%); el $11 \%$ quienes se decantan por C's; el $10 \%$ del PSOE y el $4 \%$ de Unidas Podemos ${ }^{10}$. Datos

8. P. Bréchon - F. Gonthier - S. Astor (dirs.), La France des valeurs. Quarante ans d'évolutions, Presses Universitaires de Grenoble, 2019. Las cifras que doy en el texto se basan en las que aparecen en la sexta parte del informe "La religión en movimiento».

9. Insisto en que, entre los que se sitúan en la clase social alta y media alta el porcentaje de los que se dicen católicos es del $57 \%$, el más bajo según las diferentes clases sociales como las presenta el CIS, clase social donde encontramos, lógicamente, la mayor proporción de quienes se dicen agnósticos, indiferentes, no creyentes o ateos, el $41 \%$. En el universo poblacional estas cifras son, respectivamente del $69 \%$ y del $27 \%$. Téngase en cuenta que decirse católico es un indicador más socio cultural que la asistencia regular a misa. Aquí tampoco vale la brocha gorda.

10. Repito que las cifras se refieren a quienes se han posicionados previamente como católicos. 
de todo punto previsibles, como lo son los que se ofrecen según las comunidades autónomas donde residen, pero aquí, dado el escaso número de personas entrevistadas en muchas comunidades (Murcia, 72 personas; Extremadura, 66; Aragón, 65; Asturias, 46; Baleares, 41; Cantabria, 28; Navarra, 22; La Rioja, 16), no doy cifras. Tan solo señalo que, limitándome a las comunidades donde se ha preguntado a más de 100 personas, esta es la clasificación de comunidades autónomas según la asistencia a misa, de mayor a menor: Castilla y León a la cabeza $(24,6 \%$ de practicantes dominicales), le sigue con casi las mismas cifras Castilla - La Mancha, después Galicia y Andalucía, a continuación la Comunidad Valenciana y, cerrando la lista, el País Vasco y Cataluña $(8,2 \%)$. (No hay que detenerse demasiado en las diferencias, en los datos de junio y julio de 2019. Es normal que así suceda, pues los puntos muestrales no son, ni pueden, ni deben ser los mismos. Luego dado el tamaño muestral de las encuestas en las comunidades autónomas, las fluctuaciones porcentuales en preguntas con varias posibilidades de respuesta son normales. Lo anormal, y sospechoso, sería que coincidieran).

Aquí la historia y la sociología socio-religiosa de las diferentes comunidades autónomas resultan imprescindibles para entender y analizar los datos. Pero es radicalmente insuficiente tener en cuenta un solo factor, como la industrialización, la talla poblacional o el nivel de estudios (a mayor nivel de estudios, mayor secularización), como viene sosteniendo la "vulgata» de la teoría de la socialización que, en algunos aspectos, como indican los autores de la encuesta europea de 2019 para Francia, la ponen en duda, cuando no la infirman claramente.

En la actualidad, en España es imposible no tener en cuenta el peso de la religiosidad popular, el de la emigración y la inmigración, y la historia socio-religiosa pasada y reciente. Quizá el caso catalán sea paradigmático. Hipotetizo que Cataluña, siendo la primera comunidad que se secularizó, es también la primera comunidad española que ya ha tocado fondo en la exculturación socio-cultural de lo religioso, ofreciendo la mejor respuesta al pluralismo interreligioso, aceptando la diversidad religiosa sin falsos irenismos (fenómeno que ya se observa en algunas parroquias de Madrid capital y otros lugares). Dicho sea sin olvidar ni dejar de lado que aún quedan -no solamente, pero también y con fuerza, en Cataluña- algunos núcleos, sea claramente anti-religiosos, pero de corte y razonamiento decimonónico, que, aunque con fuerte presencia mediática, se reducirán cada vez más, sea otros, ya casi residuales, que añoran una religiosidad que no va a volver y se mantienen sobre la base de unos pronunciamientos -por ejemplo, contra el papa Francisco- también decimonónicos, cuando no tridentinos. 
4. Cuatro prácticas de revitalización de las parroquias, según un estudio americano

Mientras preparo este texto, me llega un libro que propone cuatro prácticas pastorales que revitalizan las parroquias católicas. Es traducción de un libro-estudio cualitativo de entrevistas a 244 párrocos de otras tantas parroquias norteamericanas, que se distinguían por su vitalidad evangelizadora ${ }^{11}$. Siguiendo la presentación que hace del volumen en su edición española el profesor José Santiago Pons Doménech, las cuatro prácticas susodichas serían estas:

-Liderazgo compartido. El párroco comparte el liderazgo con un equipo de laicos, algunos de los cuales son incluso personal contratado por la parroquia para desempeñar una tarea que se les encomienda específicamente. Se comparte la responsabilidad en la organización y la gestión de las actividades.

-Discipulado. Se fomenta la madurez espiritual con planes específicos para crecer en el discipulado, teniendo en cuenta las distintas etapas de desarrollo espiritual de los fieles.

-Excelencia del domingo. Se cuida el domingo como día de la comunidad, dedicando tiempo, energía y dinero a las celebraciones litúrgicas, buscando la excelencia y cultivando el sentido de pertenencia a la comunidad.

-Evangelización intencional. Hay actividades explícitamente evangelizadoras dirigidas a los que no participan en la vida de la fe, programas de servicio, eventos sociales, actividades de primer anuncio, etc. (p. xv).

El libro es sumamente interesante, aun con las necesarias contextualizaciones, pues obviamente España no es América, tampoco en lo tocante a la religiosidad de sus miembros. Es un libro de ensayo, pero con base empírica, rarísima avis en España, donde lo frecuente es encontrar libros llenos de tablas y poco o ningún ensayo, o libros de mucho ensayo sin base científica alguna.

\section{SOBRE LA PIEDAD POPULAR}

\section{El Camino de Santiago}

En las últimas décadas, el interés de los investigadores por el tema de las peregrinaciones a santuarios marianos $u$ otros espacios religiosos ha aumentado significativamente. También, aunque no de la misma manera en

11. W. E. Simon Jr, Grandes parroquias católicas. Cuatro prácticas pastorales que las revitalizan, Facultad de Teología San Vicente Ferrer-BAC, Madrid 2018. 
todos los sitios, la afluencia de peregrinos. En este apartado nos centramos, muy brevemente, en el Camino de Santiago. Nos basamos en estadísticas oficiales de la Oficina del Peregrino de Santiago de Compostela, que completamos con un estudio científico de 2014 que presentamos más abajo.

\section{Los datos de la Oficina del Peregrino}

La Oficina del Peregrino solamente contabiliza los peregrinos que reciben el certificado oficial, la Compostela, es decir, que terminaron en Santiago. Estas cifras no tienen en cuenta, pues, el número de peregrinos que o no terminaron en Santiago, o no solicitaron la Compostela. En consecuencia, a las cifras que aquí aporto habría que añadir las de los peregrinos que o no terminaron, o no fueron a la Oficina del Peregrino para obtener el certificado oficial.

Según el registro oficial de 1986, el número de peregrinos era de $1801^{12}$. Conforme avanzaban los años, el número fue aumentando, especialmente a partir de 1993, que coincide con el año santo y con la declaración del Camino Francés como Patrimonio de la Humanidad por la UNESCO. Destacan los años santos como los de mayor número de peregrinos que recorren el Camino.

Centrándome directamente en las detalladas estadísticas que ofrece la propia Oficina del Peregrino, he elaborado esta sencilla estadística.

Peregrinos que acudieron a la Oficina del Peregrino de Santiago de Compostela

\begin{tabular}{|l|c|c|c|}
\hline \multicolumn{1}{|c|}{ Año } & Total & Hombres & Mujeres \\
\hline 2018 & 327378 & $49,65 \%$ & $50,35 \%$ \\
\hline 2015 & 262516 & 52,93 & 47,07 \\
\hline 2012 & 192488 & 56,53 & 43,47 \\
\hline 2010 (año santo) & 272135 & 55,75 & 44,25 \\
\hline 2007 & 114026 & 58,57 & 41,43 \\
\hline 2006 & 100377 & 59,19 & 40,80 \\
\hline 2005 & 93924 & 58,67 & 40,69 \\
\hline 2018 & 327378 & 49,65 & 50,35 \\
\hline 2015 & 262516 & 52,93 & 47,07 \\
\hline 2012 & 192488 & 56,53 & 43,47 \\
\hline 2010 (año santo) & 272135 & 55,75 & 44,25 \\
\hline
\end{tabular}

12. Me baso aquí en esta entrada digital: https://galiwonders.com/es/blog/el-caminode-santiago-cifras. 


\begin{tabular}{|l|c|c|c|}
\hline 2007 & 114026 & 58,57 & 41,43 \\
\hline 2006 & 100377 & 59,19 & 40,80 \\
\hline 2005 & 93924 & 58,67 & 40,69 \\
\hline
\end{tabular}

Fuente: https://oficinadelperegrino.com/estadisticas.

Es evidente el aumento de peregrinos desde que la oficina oficial nos ofrece estadísticas detalladas de la afluencia ${ }^{13}$, datos referidos no solo al sexo de los peregrinos, sino también a su lugar de procedencia, a si acudieron a pie, en bicicleta, etc., a los motivos que adujeron para la peregrinación (en este punto nos detenemos en el estudio que presentamos más abajo), a la nacionalidad y, en el caso de España, a la comunidad autónoma, provincia e incluso, en algunos casos, localidad desde la que comenzaron la peregrinación, al camino elegido (francés en su mayoría), a las profesiones de los peregrinos y a su edad. Una mina de información en la que no podemos detenernos aquí.

Lo hago solamente en un aspecto: la distribución de profesiones que ofrece la Oficina del Peregrino el año 2018.

Profesiones que acudieron a la Oficina del Peregrino en 2018, ordenadas en orden decreciente de frecuencia

\begin{tabular}{|l|l|l|}
\hline Empleados & 84611 & $25,85 \%$ \\
\hline Estudiantes & 58674 & $17,92 \%$ \\
\hline Jubilados & 42752 & $13,06 \%$ \\
\hline Liberales & 40785 & $12,46 \%$ \\
\hline Técnicos & 30885 & $9,43 \%$ \\
\hline Profesores & 22724 & $6,94 \%$ \\
\hline Funcionarios & 18950 & $5,79 \%$ \\
\hline Amas de Casa & 6796 & $2,08 \%$ \\
\hline Directivos & 5267 & $1,61 \%$ \\
\hline Parados & 4400 & $1,34 \%$ \\
\hline Obreros & 4005 & $1,22 \%$ \\
\hline Artistas & 2976 & $0,91 \%$ \\
\hline Religiosas/os & 1352 & $0,41 \%$ \\
\hline
\end{tabular}

13. La Oficina del Peregrino de Santiago de Compostela ofrece datos detallados a partir de 2004, año que, sin embargo, no hemos incluido en la tabla debido al número anormalmente elevado de peregrinos que ofrece: 179 944. Quizá al ser el primero han adicionado los anteriores. No lo sé, pues no lo dicen, pero no se corresponde con la serie. 


\begin{tabular}{|l|c|c|}
\hline Sacerdotes & 1315 & $0,40 \%$ \\
\hline Agricultores & 1064 & $0,33 \%$ \\
\hline Marinos & 444 & $0,14 \%$ \\
\hline Deportistas & 378 & $0,12 \%$ \\
\hline
\end{tabular}

No me resulta fácil entender cómo distinguen los empleados de los liberales (supongo que serán profesiones liberales) y los técnicos. Pero quiero subrayar algo: los obreros que peregrinan son tan pocos -no solamente en relación a empleados, técnicos y liberales, sino también respecto a los directivos y funcionarios- que la conclusión se impone: en gran parte, aunque no totalmente, por supuesto, el nivel formativo asociado a la escala profesional nos indica que, en el caso del Camino de Santiago, un mayor nivel formativo se asocia a una mayor frecuentación del Camino.

Lo que confirmaría, en esta modalidad de práctica religiosa (ciertamente ligada, en muchísimos casos, a motivos no religiosos, como constata la misma Oficina del Peregrino; volveremos en breve a esta cuestión), con una de las principales enseñanzas de la Encuesta Europea de Valores de 2018, en su aplicación a Francia, donde leemos que, manteniendo la edad constante, quienes han salido más tarde del sistema educativo son quienes en mayor proporción son católicos practicantes. El redactor de este capítulo del libro comenta así este dato: «Las relaciones entre el progreso del nivel de conocimientos y la religión son, por lo tanto, menos sistemáticas que lo que postulan enfoques corrientes del proceso de secularización ${ }^{14}$, los cuales apuntaban a que el mayor nivel de conocimientos se correlaciona con menos religiosidad. El estudio francés de 2018 infirma este dato, y la tasa de asistencia al Camino de Santiago, del mismo año 2018, aun con precauciones, pues el motivo religioso del Camino lo es en torno al $50 \%$ de asistentes, también. Allí donde hay datos científicamente contrastados, nos lleva a corregir, repito, algunas tesis sobre el proceso de secularización.

\section{Un estudio de 2014}

Nos referimos a un trabajo publicado el año 2014 en una revista especializada por tres investigadores, el español Lluís Oviedo, profesor en el Antonianum de Roma, y otros dos profesores en Oxford, realizado sobre la base de una encuesta administrada a 470 peregrinos en varios puntos

14. P. Bréchon - F. Gonthier - S. Astor (dirs.), La France des valeurs. Quarante ans d'évolutions, Presses Universitaires de Grenoble, 2019, 225. 
del Camino de Santiago ${ }^{15}$. Ya en el abstract del texto nos dicen que sus resultados confirman su hipótesis en el sentido de que las motivaciones y expectativas de los «caminantes» a menudo contrastan entre sí, no son las mismas, aun caminando uno al lado del otro en esta ruta de peregrinación. $Y$ añaden: "Sugerimos que los resultados no pueden leerse de manera simplista, ya sea confirmando una tendencia de 'post-secularización' o un renacimiento (revival) religioso».

En las conclusiones de su trabajo son todavía más explícitos. Escriben: «Nuestros datos indican claramente que la mayoría de los peregrinos no están particularmente interesados en la religiosidad tradicional. Sin embargo, es difícil leer los resultados como una clara señal de cambio espiritual. Hay signos claros de la presencia de formas eclécticas de espiritualidad, pero esto se asocia con un deseo o búsqueda de nuevas sensaciones. Sugerimos encuadrar los resultados considerando dos tipos principales de peregrinos, que corresponden aproximadamente a lo que Taylor (2007) describió como el ser 'poroso' y el yo 'amortiguado'. Mientras que el primero se refiere al individuo integrado en un cosmos de significados y valores religiosos, el 'yo amortiguado' corresponde a la persona moderna, flexible y adaptable a cada contexto, sin estar integrada o subsumida en un cosmos de significado mayor. El Camino proporciona un contexto en el que ambos tipos coexisten: uno integrado en un universo religioso de símbolos, y el segundo construyendo su propio universo de significados y referencias, no conectado de manera inmediata con un marco predeterminado, pero que se adhiere de forma vaga o confusa a experiencias y sentimientos. El segundo tipo de peregrino es predominante en nuestra muestra».

Este planteamiento de 2014 coincide con algunas de las conclusiones del capítulo socio-religioso de la Encuesta de Valores Europea en su aplicación en Francia el año 2018, que ya hemos referenciado, donde podemos leer que «el análisis de las creencias revela que la creencia en Dios va mucho más allá de la identificación con una religión establecida. Más que un retroceso de la religión en Francia, deberíamos hablar de desinstitucionalización de la religión, y aumento de los cultos minoritarios». Y añaden que «las teorías del fin de la religión no están confirmadas por esta nueva versión de la encuesta sobre los valores de los europeos, y de los franceses en particular. Sin embargo, las Iglesias históricas parecen sufrir un creciente desprestigio» ${ }^{16}$.

15. L. Oviedo - S. de Courcier - M. Farias, Rise of Pilgrims on the Camino to Santiago: Sign of Change or Religious Revival?: Rev Relig Res 56 (2014) 433-442.

16. P. Bréchon - F. Gonthier - S. Astor (dirs.), La France des valeurs, 223ss. 
Nosotros ya abordamos esta cuestión de la desinstitucionalización de lo religioso y la contrapusimos a la subjetivación de la fe en nuestro trabajo sobre la Iglesia, comentando la última publicación de Peter Berger ${ }^{17}$. El Camino de Santiago se nos aparece como un caso paradigmático de construcción de sentido, de encuadramiento, aún muy abierto y en continua recomposición, de la demanda de espiritualidad (por usar un término al uso) en una sociedad secular, que, al devenir secularista, ya ha mostrado sus límites.

\section{El santuario de Lourdes y el musical «Bernadette de Lourdes»}

En la propia web del santuario de Lourdes, en la presentación oficial del musical «Bernadette de Lourdes», a partir de julio de 2019, se podía leer esto: «Lourdes recibe a cuatro millones de peregrinos cada año. El espectáculo musical Bernadette de Lourdes ha sido diseñado especialmente para ellos. Jóvenes o ancianos, curiosos, creyentes o no creyentes, enfermos, todos son bienvenidos, y el transporte está organizado para facilitar el acceso a la sala. El espacio de Robert Hossein tiene la mayor capacidad en Europa para personas con movilidad reducida o discapacitados» ${ }^{18}$. Más abajo diré dos palabras sobre el musical. Pero antes, unas informaciones sobre la frecuentación de peregrinos y visitantes a Lourdes y su evolución.

De hecho, como ya señalaban los propios responsables del santuario en 2012, «el modelo de la peregrinación organizada de Lourdes se encuentra hoy en día en dificultad. Las penosas condiciones del transporte ferroviario para los enfermos, el aumento del coste de la vida, la descristianización de nuestra sociedad occidental son obstáculos que los organizadores de peregrinos deben superar ${ }^{19}$. Es con fe y tenacidad como resisten para perpetuar la tradición del peregrinaje colectivo.

Volviendo a la información de 2019, con la que abríamos este punto, leemos, en palabras del obispo de Lourdes, Nicolas Brouwet, que la caída de asistencia organizada es espectacular. Dice: «Con los grupos, pasamos de 800000 peregrinos en 2010 a 450000 en 2018. En concreto, un $27 \%$ menos entre los franceses, un $59 \%$ menos entre los italianos». El obispo apunta a unos datos, elaborados sobre los 23 días internacionales St. François de Sales, de finales de enero de 2019 en la ciudad mariana. Pero me apresuro a decir que esas cifras se corresponden con los datos oficiales de peregrinos

17. J. Elzo, Morir para renacer. Otra Iglesia posible en la era global y plural, San Pablo, Madrid 2017, 50ss.

18. https://www.cath.ch/newsf/lourdes-baisse-de-frequentation-et-defis-pastoraux (consultado el 24 de julio de 2019).

19. http://www.lourdes-infos.com/65100lourdes/IMG/pdf/frequentation_2012_v4_0.pdf (consultado el 24 de julio de 2019). 
registrados en las oficinas oficiales del santuario, pues muchos peregrinos vienen individualmente o en pequeños grupos sin previo aviso, sin olvidar a los que simplemente vienen como turistas o participantes de un circuito, para los que la dimensión religiosa apenas tiene importancia. Lo que hace decir al obispo que, «sin sacerdote, sin supervisión, se enfrentan a un nuevo desafío para la animación pastoral: ¿Cómo pasar del cristianismo popular al acompañamiento individual del cristiano? A partir de ahora, una buena parte de los peregrinos llegan sin previo aviso, ni anuncian la duración de su estancia. ¿Cómo unirse a ellos?».

Pero, insistimos, la mayoría de personas que frecuentan el santuario lo hace al margen del registro oficial. El $80 \%$, según los responsables del ya mentado trabajo de 2012, al par que nos indican que, desde 2001, se instauró una operación de control de «peregrinos y visitantes» muy sofisticado, por parte de los servicios de seguridad, sacristanes, etc., sea a la gruta, sea a las misas u otras celebraciones. Así, en 2012 contabilizaron 6024222 de personas en la zona religiosa de Lourdes, «una bajada del $4,25 \%$ respecto del año anterior».

Además, la proporción de peregrinos europeos es cada vez menor, mientras que aumentan los que proceden de más allá de los mares, sea en Asia (Filipinas, India, Sri Lanka), sea Sudamérica. Estos visitantes están cambiando el juego. "Por ejemplo, nuestro cinturón de antorchas la Navidad pasada reunió al $90 \%$ de extranjeros», dice el obispo Brouwet. Y añade: «El desafío para nosotros es pasar de una pastoral centrada en los europeos a dar la bienvenida a peregrinos de todo el mundo».

Otras cosas están cambiando también. Por ejemplo, la hospitalidad tradicional a los enfermos en Our Lady's Home, un vasto y hospitalario recipiente frente a la gruta, recibe la mitad de los pacientes. Prefieren quedarse con su grupo a separarse de él. Como resultado, a menudo se alojan en el hotel con sus compañeros. "Es una novedad, porque siempre los hemos tratado aparte», dice el obispo Brouwet.

Y la piscina, que llegó a ser poco atractiva, se ha convertido en un pasaje popular. «ilncluso entre los jóvenes!», afirma el obispo de Lourdes. «Porque buscan acciones concretas que comprometan sus cuerpos. Donde sus mayores vieron superstición, para los jóvenes tener frío, estar mojados, ¡está bien!». Lo mismo para las tiendas de recuerdos, tan numerosas en la ciudad mariana. "Para los jóvenes, estos son derivados, como se ven en Disneyland».

También las familias llegan a Lourdes de manera diferente. La mezcla de turismo y peregrinación obliga a repensar la recepción. Con exigencias a las familias, muchas veces descuidadas en el pasado. Quieren vivir en la 
ciudad pirenaica con cierta autonomía, sin formar parte de un grupo y quedarse en el hotel. Ellos reclaman aparta-hoteles ${ }^{20}$.

Los responsables del Santuario indicaban el año 2012, como objetivos centrales para el futuro de Lourdes, estos seis puntos: acompañar a los peregrinos individuales en su visita; preservar el recogimiento en la gruta; continuar en el acompañamiento a los enfermos; continuar con la reflexión acerca del transporte a Lourdes; abrir el mensaje de Lourdes mediante las nuevas tecnologías y renovar el modelo económico.

En la actualidad, al margen del transporte por tren, tema en el que dudo que hayan podido hacer algo, parece que avanzan en los demás. Las cuentas deben estar ya saneadas y, respecto de las nuevas tecnologías, desde el 1 julio de 2019 se emite el musical Bernadette de Lourdes. Así lo presentan, desde el Santuario:

El espectáculo musical Bernadette de Lourdes narra fielmente la historia de Bernadette durante las apariciones. El itinerario de una adolescente débil cuyo destino cambia radicalmente en un instante. Tomando las palabras y documentos auténticos de la época, Bernadette de Lourdes recuerda fielmente la cronología de los acontecimientos, su familia, su encuentro con la Virgen María, su lucha humilde, tranquila y determinada por defender los hechos. Una historia extraordinaria que permanecerá para siempre en nuestros corazones y que nos llevará de la gruta de Massabielle al calabozo, pasando por comisaría.

El diario católico La Croix iniciaba su reportaje tras el estreno del musical con estas palabras del sacerdote André Cabes, rector del santuario de Lourdes: «Voilà, c'est Lourdes. L'essentiel est là». El rector estaba emocionado a la salida de la primera representación del espectáculo musical sobre santa Bernadette el lunes 1 de julio, al igual que los 1500 espectadores que habían Ilenado la sala. Reporta La Croix el testimonio de «Danièle, atea, con lágrimas en los ojos, impresionada por la historia de la pequeña vidente de Lourdes». El director de escena del musical, Serge Denoncourt, declara que «también para los no creyentes (Bernadette) es una figura femenina que marca la historia de Francia. Como Juana de Arco sin armadura» (La Croix, 2.7.2019). En los cinco próximos años, este musical se representará de abril a octubre en el santuario mariano y en diversos países, incluido España.

20. No es este el lugar para explayarse en este tema que a mí también me ha interpelado, en las familias de mis hijos, al constatar el cuidado con el que miman estar con frecuencia ellos solos: padre, madre e hijos. Cuando este verano nació mi quinta nieta, una madrugada de junio, sus padres decidieron que la tarde del día del nacimiento querían estar ellos solos con sus dos hijas mayores y la recién nacida, para vivir la experiencia del nuevo miembro de la familia en familia, los cinco en la habitación del hospital. Nos indicaron que así lo comunicáramos a todos. ¡No!, la familia no ha muerto, bien al contrario. Claro que, como siempre, hay familias y familias. 
La evaluación de esta experiencia se hará en su momento, como evalúan continuamente la afluencia de "visitantes y peregrinos» al santuario de Lourdes. Pero ya se puede concluir que Lourdes sigue vivo, adaptándose a los tiempos actuales.

\section{La Semana Santa de Priego de Córdoba}

La religiosidad en un mundo secularizado persiste en la medida en que las prácticas sociales en las que se manifiesta siguen teniendo algunas funciones sociales y culturales o individuales; por tanto, su desaparición o persistencia en este caso que nos ocupa en España, y más concretamente en Andalucía, están en relación directa con su utilidad y funcionalidad en el campo de las identidades colectivas, la integración, la dimensión festiva, la experiencia de la sociabilidad, y en la satisfacción de necesidades materiales, espirituales, terapéuticas y de oferta de sentido global a la vida. Las religiones que no aportan nada terminan desapareciendo; $y$, dentro de cada religión, las prácticas religiosas que desaparecen son aquellas que no significan nada o que no movilizan a los individuos o a los grupos, especialmente a aquellos que son más activos o que están llamados a ser gestores de esa sociedad, como es el caso de los jóvenes. Sobre esto estamos trabajando mucho los antropólogos desde comienzos de los años 80 , no sin ciertas manifestaciones de malestar por parte de los obispos que, celosamente, creían ser los únicos actores con derecho a estudiar el patrimonio religioso católico ${ }^{21}$.

Cabe señalar dos ámbitos de persistencia del «catolicismo popular». Por un lado, se trata de la recepción de los sacramentos en las transiciones vitales: nacer, crecer, casarse y morir, que siguen siendo gestionados en las parroquias por la jerarquía católica, en los bautizos, primeras comuniones y confirmaciones, bodas y entierros. «Estas celebraciones vitales dan pie a una serie de manifestaciones rituales religioso-festivas que convocan, reúnen y refuerzan la pertenencia e identidades de las redes familiares amistosas y vecinales» (p. 212). Pero los trabajos sociológicos recientes muestran que estas celebraciones de los ritos de paso están descendiendo de forma continuada en Europa occidental y también en España, aunque a ritmos diferentes según las regiones.

El otro ámbito de persistencia religiosa católica del «catolicismo popular», apunta Briones, lo constituyen otra serie de prácticas liberadas, en cierto modo, de la tutela de la jerarquía. Se trata de rituales y formas de pertenencia en los que los seglares -identificándose unos como creyentes y otros como

21. R. Briones Gómez, Persistencia del Catolicismo Popular en la España secularizada: el caso de Andalucía y de sus Semanas Santas, en J. I. Urquijo Valdivielso - T. Calvo Buezas (eds.), El hecho religioso en España hoy. Del nacionalcatolicismo al pluralismo religioso, Eunate, Pamplona 2018, 209. 
no creyentes- son los protagonistas, teniendo un gran margen de gestión en la forma de llevarlos a cabo. Concretamente me refiero a las siguientes prácticas: fiestas patronales de pueblos, barrios o corporaciones; romerías o peregrinaciones a santuarios con un fuerte componente ecológico, festivo y de sociabilidad; pertenencia a cofradías y hermandades, con el consiguiente desarrollo de procesiones, preparación de las mismas, actos y actividades organizadas por las hermandades a lo largo del año para el culto, la formación y la sociabilidad y la convivencia, como, por ejemplo, días de ocio y diversión en el campo o en la ciudad, para comer y beber juntos. Resaltan, sobre todo en Andalucía y en otras ciudades de otras comunidades autónomas, los rituales que tienen lugar durante la Semana Santa. "Como puede verse, este tipo de prácticas religiosas y profanas del catolicismo popular pivotan en torno al concepto de fiesta, de la tradición, de las emociones y de las costumbres locales de las fiestas religiosas; en una época de secularización y de descatolización, son seguidos aún por una inmensa mayoría de la sociedad española» (p. 212-213).

A veces se suelen dar explicaciones simplistas, parciales, que no convencen o que están más cargadas de ideología que de análisis riguroso. Se dice, por ejemplo, para explicar la persistencia de las prácticas del catolicismo popular, que la gente no va allí por religiosidad, sino por folklore, como si religiosidad y folklore fueran radicalmente incompatibles. «Esta explicación la he oído proponer frecuentemente a personas detractoras del catolicismo popular, bien con intenciones integristas católicas, al considerar que no son formas auténticas de expresión religiosa, sino prácticas que rayan en la superstición, la magia o el desenfreno. Otras veces las intenciones latentes eran laicistas, en personas contrarias a todo tipo de religiosidad» (p. 213). En realidad, me permito añadir, no hay actos de religiosidad pura. Toda religiosidad está necesariamente encarnada en la humanidad que la manifiesta. ¿Es que la masiva asistencia a misa de cuando éramos adolescentes, los años 40 y 50 del siglo pasado, eran actos puramente religiosos? Y cuando nos llevaban a confesarnos los primeros jueves, casi en fila india, de la escuela a la parroquia, ¿era un acto exclusivamente religioso?

La explicación que se propone para la persistencia de algunas manifestaciones del denominado catolicismo popular «está en la línea funcionalista y hermenéutica simbólica de la antropología social; no entra en un planteamiento filosófico y menos aún teológico. Me interesa la religión como 'hecho social total' y busco sus causas y sus efectos viendo a estos hechos como variables dependientes y también independientes desde un planteamiento global (Mauss). En el caso que me ocupa, creo poder dar una explicación desde unas decisiones individuales, sociales y culturales que se ven satisfe- 
chas en estas prácticas; esto no supone que la explicación dada sea la única posible; en todo caso, es una explicación que se puede verificar empíricamente. Otras explicaciones más ambiciosas son posibles, pero vendrán de argumentos no verificables empíricamente y que se moverían en el ámbito de las justas opciones emocionales o ideológicas (Estrada)» (p. 215).

Y remacha en la página siguiente su explicación escribiendo que «estas prácticas residuales en el contexto actual de secularización son también ocasión de vivir la necesidad antropológica del 'tiempo extraordinario' en la fiesta, con sus funciones de exhibición estética, de liberación psicológica, de reactivación de la economía y de reafirmación de las identidades sociales y culturales a niveles grupales, locales, regionales y nacionales» (p. 216).

El autor de estas reflexiones, Rafael Briones, antropólogo, cita al gran maestro de la antropología M. Mauss. El sociólogo que es uno, recuerda a Durkheim, uno de los dos padres fundadores de la sociología (con Max Weber), cuando solicita analizar los hechos sociales como cosas, analizadas desde sí mismas y desde la lectura y uso que hacen de ellas los actores sociales. Y esto es lo que pone de relieve Briones en su trabajo. Se desplaza allá donde tiene lugar su objeto de estudio (que concretará más adelante en la Semana Santa de Priego de Córdoba y, más en concreto, con la subida al Calvario, la mañana del Viernes Santo, de Jesús el nazareno de Priego), y mediante procesos empíricos verificables ofrece su explicación, obviamente limitada, como lo es siempre en la ciencia, al trabajo de campo realizado y a los instrumentos utilizados. Briones tiene buen cuidado en señalar que su explicación no agota todas las explicaciones posibles, pero sí que la suya es comprobable.

Algunos ven en este punto como una divergencia entre las ciencias empíricas y las teológicas, pero no hay tal divergencia, si se pretende que la teología sea también una ciencia. Me explayé sobre este punto en la introducción a uno de mis libros, el menos leído de los que escribí ya jubilado de dar clases y me consagré, con nulo éxito, al ensayo fundamentado. Escribí que «la fe, y en particular la ciencia teológica, por un lado y las ciencias sociales (las ciencias en general), por el otro, tienen sus reglas de juego, su autonomía propia, pero no conforman dos comportamientos estancos. Nunca he visto las expresiones 'sociología teológica' o 'teología sociológica', pero quizás un día me plantee su verosimilitud. En todo caso, sostengo que la teología no puede desprenderse, en sus formulaciones, del contexto sociocultural en que nacieron y en la lectura que se hace de las mismas en los espacios donde y cuando se leen. Así mismo, una sociología del hecho religioso no puede no tener en cuenta las formulaciones teológicas que se proponen en el diálogo intelectual, en las propuestas a los creyentes y en la 
lectura que estos hacen de las mismas. Pero, más aún, un sociólogo (o un científico social) que se diga creyente no puede situarse, a veces como sociólogo, a veces como creyente, en su despacho de trabajo como sociólogo, los domingos en la eucaristía como creyente ${ }^{22}$. Lo voy a decir con las palabras de Daniele Hervieu-Léger, socióloga francesa con quien tuve el gran placer de trabajar en un periodo demasiado breve de mi vida. Dice Daniele que, «como científica, mi ambición es la de reducir la experiencia religiosa a un mecanismo social. Pero tropiezo siempre con el tope de mi fe (je me heurte toujours au boutoir de ma propre foi), que la sola sociología no puede explicar. Luego me he visto obligada a reconocer que yo soy socióloga de las religiones y creyente. La cuestión no es tan paradoxal como parece. La fe, como la sociología, es un deambular crítico. Los dos abordajes son compatibles, cada uno puede dar sentido al otro. Creer es liberarse sin cesar de las ilusiones religiosas, esto es, no confundir nuestras imágenes de Dios con Dios mismo» ${ }^{23}$.

Hay que subrayar la idea de que el abordaje crítico, con las armas de la razón y la experimentación, personal y participada, es válido y necesario tanto para la fe como la ciencia. No para hacer un totum revolutum de las creencias religiosas y de las «verdades» científicas (quizás sería más exacto decir «hallazgos científicos»), que guardan cada una su propio espacio de conocimiento. No estamos en el mismo campo epistemológico cuando hablamos de «la acción de Dios» (quien se atreva a hacerlo), o de los quanta de Planck, aunque no falten eminentes físicos que se hacen preguntas relacionando ambas cuestiones... Pero en los dos campos es legítimo el abordaje científico, en cuanto no solamente (aunque también) va depurando las ilusiones que la historia, personal y colectiva, han depositado sobre la verdad religiosa o la empírica, sino también porque, como ya dijera John H. Newman, yo solamente puedo pensar con mi cabeza como solamente puedo respirar con mis pulmones. De Dios solamente puedo hablar con lo que mi cabeza y mi experiencia vital me den. Exactamente igual que un científico en su laboratorio. Es cierto que el científico «toca», «mide», "cuantifica» lo que experimenta. Esa es su fuerza y su limitación, pues la realidad no se agota en lo que se puede tocar, medir, cuantificar, etc. Por eso está en el ADN del pensamiento científico, digno de ser enten-

22. J. Elzo, ¿Quién manda en la Iglesia? Notas para una sociología del poder en la lglesia Católica del siglo XXI, PPC, Madrid 2016, 11-13.

23. Esta afirmación proviene de una entrevista en La Vie, 19 de septiembre de 1996, recogida en un libro sumamente interesante: J. Palard (dir.), Le gouvernement de l'Eglise Catholique. Synodes et Exercice du Pouvoir, Institut d'Études politiques de Bordeaux, Cerf, Paris 1997, 19. 
dido como tal, su carácter temporal, parcial hasta que otra investigación, otra teoría (pensamiento) infirme, supere, matice, rechace, etc., la verdad científica del momento. Por eso prefiero el término «hallazgo científico» al de «verdad científica», verdad siempre provisional, sujeta a ajustes, nuevas verificaciones, confirmaciones e infirmaciones. Lo mismo sucede, o debiera suceder, como método de aproximación, como abordaje, en el conocimiento religioso. ¿Es que no sabemos hoy que Pablo estaba equivocado cuando pensaba próxima la venida del Señor? Y quizás el mismo Jesús, se preguntan algunos estudiosos del Jesús de la historia.

\section{El Congreso de Padua de octubre de 2012 sobre la religiosidad popular}

Un amigo sacerdote, teólogo, que domina el italiano, me traslada las conclusiones más importantes del congreso sobre la religiosidad popular celebrado los días 19 y 20 de octubre de 2012 en Padua, con la participación de sociólogos y semiólogos tanto italianos como extranjeros, tal y como refiere Luigi Berzano, sacerdote y profesor del Departamento de Sociología de la religión en la Universidad de Turín ${ }^{24}$. Apunta a tres cuestiones diferentes:

- La primera, la actualidad de la religiosidad popular: algo así como si se estuviera asistiendo al renacimiento de la religión de siempre.

- La segunda, la creciente presencia de peregrinos pertenecientes a las clases medias y altas, al mundo juvenil, además de no creyentes y de creyentes de religiones no cristianas.

- La última, lo que el congreso ha definido como «la generatividad cultural y espiritual de los santuarios». Se están gestando unas pautas diferentes de lo que se entendía hasta ahora por religiosidad popular como si fuera algo residual del pasado, o una forma pintoresca de inautenticidad. Además, lo que está emergiendo no tiene nada que ver con lo que es solo propio de las clases subalternas.

\section{La actualidad de la religiosidad popular}

Más allá de las discusiones acerca de la desaparición o regreso de la religión en las sociedades modernas, la religiosidad popular siempre ha permanecido firme y viva. Ha sobrevivido, en una especie de clandestinidad, fuera de los sistemas teológicos que enfatizaban la racionalidad, y al margen de quienes preconizaban el triunfo de la técnica, la ciencia y la laicidad.

24. En esta publicación se recogen las aportaciones principales del Congreso: L. Berzano - A. Castegnaro - E. Pace, Religiosità popolare nella società post-secolare. Nuovi approcci teorici e nuovi campi di ricerca, EMP, Padova 2014. Puede verse un resumen en la web del Foro de curas de Bizkaia. 
La investigación presentada durante el congreso en Padua constató que la religión popular reaparece en la transversalidad social, cultural, anagráfica (datos personales) e incluso religiosa de los peregrinos. En los nuevos peregrinos hay jóvenes, adultos y ancianos, mujeres y hombres, con muchos y diferentes niveles de formación, italianos y extranjeros, católicos practicantes y no practicantes y, más recientemente, cristianos y no cristianos.

Esta transversalidad contrasta con la idea de que la religiosidad popular es algo propio de clases sociales con una incuestionable limitación cultural o con una sensibilidad muy definida. A partir de la transversalidad detectada, se comprende la gran variedad de motivaciones que mueven a los peregrinos en su devoción por san Antonio.

Entre los peregrinos se encuentran quienes buscan una gracia, quienes, habiéndola recibido, necesitan manifestar su reconocimiento y consolidar la relación, la confianza y la esperanza de ayudas futuras. De los datos presentados en la investigación se concluye que las motivaciones de ayuda y protección son el $47,9 \%$, las de agradecimiento el $25,2 \%$, las de devoción y fortalecimiento el $22 \%$, las de participación casual el 4,9\%.

Otras investigaciones, según el resumen de la conferencia que realiza Luigi Berzano, sobre los peregrinos en los grandes santuarios terapéuticos como Fátima y Lourdes han evidenciado que la gracia recibida se manifiesta tanto en la resolución del problema como en la habilitación de la fuerza necesaria para afrontarlo y aceptar -si fuera preciso- la situación de riesgo. Nada que ver, por lo tanto, con el hombre primitivo que esperaba la lluvia después de haber realizado el ritual previsto, y sí mucho que ver con el hombre que busca la fuerza moral para afrontar y aceptar su futuro.

\section{Los diferentes perfiles de los peregrinos}

La segunda conclusión es la mayor presencia de peregrinos de la clase media en comparación con las clases trabajadoras. La investigación realizada desmiente todos los tópicos sobre la devoción popular: que es una forma de religiosidad propia de ancianos, de personas poco secularizadas

y con escasos recursos. Ya no es el pueblo de las clases inferiores, sino toda la sociedad la que participa -si bien en formas, tiempos y modalidades diferentes- en la vida de los santuarios.

Pasar un día en un santuario observando a los peregrinos durante los rituales individuales y colectivos confirma un ulterior elemento: no se trata de una religión intelectual, sino de una religión de los sentidos. Todas las prácticas tienen una fuerte referencia a los sentidos: el olor de los inciensos y la cera de las velas; las manos que tocan los mármoles, las balaustradas y 
los relicarios; los cantos, la música del órgano y el murmullo de las oraciones entre los cuchicheos de los peregrinos; el peregrino en pie o arrodillado, las manos levantadas o juntas, la cabeza sobre el gran relicario que custodia el cuerpo del Santo...

En la religiosidad popular todo está al servicio del homo videns que mira, contempla, se sumerge en la penumbra, en los colores difusos o en la luz plena. Todo se ofrece al peregrino para que lo haga suyo, lo adapte a los modos y formas que le emocionen.

La religión popular siempre ha estado presidida por el principio según el cual los hombres conocen lo invisible por medio de lo sensible (lo que ya defendía la teología escolástica cuando afirmaba que no hay nada en el intelecto que previamente no haya pasado por los sentidos). Por eso, el sentido se expresa mediante prácticas corporales que también pueden ser objeto de discurso racional. Pero la centralidad de las prácticas rituales no presupone que no se transforme su sentido con el paso del tiempo.

\section{Cómo cambian los santuarios}

La pregunta que cabe formularse es la de saber de qué manera la religión popular promueve la comunidad civil o eclesial en un territorio concreto como puede hacerlo la parroquia. Es evidente que cuando se pone en valor un santuario, una abadía románica, un santo popular, un monte sagrado o una cruz campestre, se está contribuyendo a regenerar una zona y se está relanzando, igualmente, la economía de una comunidad. Pero ¿desde el punto de vista más específicamente religioso?

Las buenas intenciones no son suficientes para tener éxito. Cabe decir que la religiosidad popular activa sus potencialidades espirituales a condición de que «se le deje desarrollar su propia y peculiar capacidad, ya sea para inventar la vida cotidiana, ya sea para generar meta-relatos».

La religión popular es la experiencia del mundo religioso de manera personal y colectiva, emotiva e intuitiva, creativa y horizontal. Su secreto consiste en ser la religión que sabe "estar a la altura de lo cotidiano», como diría Max Weber, es decir, a la altura de lo que está en la base del existir: el vivir juntos, la horizontalidad fraterna, el hombre en relación con el grupo, la naturaleza, lo sagrado. No otra cosa escribe, con fuerza, el antropólogo Rafael Briones, como hemos indicado más arriba, en su trabajo sobre el catolicismo popular en Andalucía que lo sitúa en «relación directa con su utilidad y funcionalidad en el campo de las identidades colectivas» ${ }^{25}$.

25. R. Briones, Persistencia del Catolicismo popular en la España secularizada, 209. 
Concluyamos con la investigación de Berzano, trasladando sus conclusiones, tal como nos las transcribe la web del Foro de curas de Bizkaia: «La pregunta sobre la capacidad creadora de la religiosidad popular remite a la de la generatividad espiritual y cultural de los lugares sagrados, de las tradiciones seculares, de los grandes símbolos, de las milenarias memorias de los santos, de los misteriosos relicarios y también de las multitudes de peregrinos postmodernos.

También la construcción de un 'meta-relato' en torno a un santo, a un santuario, a un milagro (a pesar de tantas declaraciones de desaparición de todos los meta-relatos) los dota de fascinación y valor. El plus de sentido de un bien cultural y religioso depende del marco simbólico, estético y mítico que se construye a su alrededor».

Es lo que buscan en el santuario de Lourdes con el musical Bernadette de Lourdes, con gran éxito, al menos en los meses que se lleva proyectando en una sala aneja al propio santuario.

\section{Elementos diferenciales del Día del SeÑor y de LA PiedAd POPULAR}

Llego ya a este punto del presente texto, para cerrarlo, que no concluirlo, con unas pocas notas finales que son básicamente subrayados de lo que he expuesto a lo largo de las paginas precedentes, ciertamente excesivas. Pero necesitaba, yo mismo, sobre todo en lo que a religiosidad popular se refiere, informarme aunque fuera sucintamente sobre el tema, pues de la práctica religiosa dominical tenemos más información. Pero esto no es una tesis doctoral.

Mirando al futuro, y limitándonos al campo de nuestro estudio, el suroeste de Europa occidental, básicamente Italia, Francia, España, Portugal y quizá Bélgica, cabe decir que en el futuro muchas parroquias, en el modelo actual (con un sacerdote al frente), desaparecerán, en gran medida por falta de sacerdotes, sin que se vea en la actualidad un incremento de vocaciones religiosas, al menos a corto plazo. Algunos autores hablan del fin de la era parroquial y, como he referido en el texto, ciertamente lo es en el modo como lo hemos conocido en los últimos siglos.

Pero también hay que añadir que hay parroquias y parroquias. Además del trabajo americano que hemos mencionado en el texto, una simple observación muestra que en España hay parroquias que llegan al «pleno empleo» los fines de semana, mientras que otras están casi vacías los domingos, incluso en las grandes y medias ciudades, donde habita la mayor parte de la gente. Salvo ignorancia por mi parte, no conozco estudios que aborden con rigor científico este tema en España. 
En todo caso, es más fácil, logísticamente hablando, mantener vivo un espacio religioso cargado de un simbolismo particular, que cien parroquias en una diócesis media con la actual penuria del clero, a lo que hay que añadir, y sobre todo no olvidar, que la significación de la práctica religiosa, en particular «ir a misa los domingos», no tiene, en absoluto, en la actualidad el mismo significado para el común de los católicos (de quienes se dicen católicos) que el que tenían hace cincuenta y más años. Pues en este breve periodo de tiempo hemos transitado de la era de la cristiandad a la era secular, lo que explica muchas cosas.

Subrayaría de forma telegráfica unas diferencias elementales, luego fundamentales, entre la práctica parroquial dominical y la religiosidad popular, exclusivamente desde la vertiente sociológica. Para la teológica, puede ver el texto de cardenal Kasper en el tercer excursus del presente texto.

\section{Sobre las parroquias}

1. En el ámbito parroquial cabe hablar de una relativa estabilidad de los fieles. En teoría hay una posibilidad de una formación en intensidad y profundidad; catequesis de niños, jóvenes y adultos, aunque los escasos estudios al respecto muestran su debilidad ${ }^{26}$.

2. En una parroquia hay una posibilidad teórica de crear una comunidad. Ese es, al menos, uno de sus objetivos: la comunidad de fieles del tal o cual parroquia y, en esta época de penuria de sacerdotes, de tal o cual zona que comprende varias parroquias limítrofes en una ciudad, incluso mediana.

3. Hasta ahora y en gran parte todavía, es posible hacer un seguimiento de una persona, teóricamente, desde el bautismo hasta el fallecimiento. Y si no es a lo largo de toda una vida, sí al menos durante periodos relativamente largos de la vida de las personas. Luego es posible llevar a cabo un acompañamiento espiritual, imposible en una peregrinación puntual o anual.

4. En este punto quiero señalar la importancia del acompañamiento sin más, sin adjetivos, de determinadas personas que, por diversas razones, pueden necesitar ayuda. Por ejemplo, a muchas personas les cuesta entrar en contacto con la administración pública, cada día más protocolizada, más informatizada y con un acceso cada vez más complejo, incluso para personas con buena formación. La administración es imperial y laberíntica, incluso, insisto en ello, para personas con formación. Si además no la tienen o, simplemente, son personas mayores, una de las mejores labores que puede

26. Véase el libro de Félix Garitano 25 años de vida parroquial, Kutxa, San Sebastián 2018. Me temo que este libro forma parte de las publicaciones casi-clandestinas, pues no lo encontrarán en ninguna librería no especializada en temas religiosos. 
hacer el voluntariado, en este caso cristiano, es ayudarles. No por nada se ha puesto de modo la ética de la compasión, hasta el punto de que un mediático teólogo ha afirmado que «la compasión es la opción fundamental de Jesús de Nazaret».

5. Ciertamente hay un riesgo de rutinización en la práctica parroquial por la ritualización de la eucaristía dominical. Además, y muy frecuentemente, con lecturas que la mayor parte de los fieles no entienden. No me sirve escuchar que es "palabra de Dios», que lo es, pero es palabra de Dios dirigida a mujeres y hombres de hace muchos siglos, con otra cultura hoy inexistente.

6. No hay que olvidar que vivimos en el imperio del individualismo, y que algunos, de los pocos con menos de 65 años que van a la iglesia los domingos, seleccionan su parroquia.

7. No olvidar las consecuencia no queridas del principio tan en boga, en los finales de los años 60 y primeros de los 70 , cuando se produce el gran cambio (la gran aceleración del gran cambio) de la era de la cristiandad a la era secular, que venía a decir que "se puede ser buen cristiano sin ir a misa», lo que influyó enormemente en el desenganche de los católicos practicantes, precisamente, de la práctica religiosa dominical.

\section{Sobre la religiosidad popular}

1. La religiosidad popular siempre ha estado ahí. No es una realidad de nuestros días. Pero estaba, a veces, como agazapada, como cosa de sentimientos, de gente sin formación y, a veces, también vista como próxima si no a la superstición, que también, sí enfrentada a una religiosidad marcada por la inteligencia de la fe. Era vista con prevención no solo por parte de algunos obispos y sacerdotes, sino también por la gente intelectual o de elevada formación académica. Como cosa de gente inculta.

2. Pero los datos que tenemos sobre la práctica actual de la religiosidad popular nos muestran que en ella participan personas de toda condición social y cultural, como hemos mostrado en el texto en el caso del Camino de Santiago y lo reflejan las conclusiones del Congreso de Padua.

3. Es fundamental tener en cuenta que muchas manifestaciones de piedad popular responden a demandas expresas, sean explícitas o implícitas, de los propios fieles. Son manifestaciones que responden a necesidades sentidas por los propios ciudadanos. Estas «necesidades» pueden ser de muchos signos: de petición de ayuda; de encontrarse en un ámbito de fraternidad, de encuentro emocional, en un contexto determinado (un lugar con especial fuerza espiritual, Lourdes, Guadalupe, el Pilar, etc.); necesidad de expresar y vivir emociones y sentimientos; necesidad de identificarse con 
una tradición ancestral de su localidad o región, que ayuda a fortalecer una identidad; necesidad de dar gracias por un bien recibido etc. En este punto, las reflexiones del antropólogo Rafael Briones son de un impagable valor y nos muestran el valor de la explosión emocional y de los sentidos que están en la base de la piedad popular.

4. En este orden de cosas, me viene a la cabeza una reflexión personal en alguno de mis trabajos sobre la religión entre los jóvenes, donde manifestaba algo como esto: los jóvenes solamente aceptan la dimensión religiosa en la medida en que les ofrezca algo útil para sus vidas. Y debí añadir algo como esto: una religión que no sirva para la vida, que no sea útil para la vida, es una religión inútil y acabará desapareciendo. Sigo pensando lo mismo, aunque no se entienda los términos «útil» y «utilidad de la religión» en el sentido más rastrero.

5. Mucha gente acusa a la piedad popular de mezclar la dimensión religiosa con la secular y, más concretamente, la secular próxima, la relacionada con la vida civil en la que se inserta la piedad de los asiduos a la piedad popular. Ante tal «acusación», lo primero que digo es que no puede ser de otra manera, como tampoco lo era la masiva frecuentación al día del Señor hace sesenta y más años. Muchas personas asistían a misa los domingos, como he mostrado en el cuerpo de este texto, sencillamente porque formaba parte del uso del tiempo ordinario, hasta el punto, lo repito aquí, de que incluso se ofrecían misas de madrugada en las estaciones de tren para los montañeros y cazadores. Vivíamos en el estado de cristiandad, en un catolicismo sociológico o cultural, como hoy se vive un ateísmo o un indiferentismo tan sociológico o cultural en la era secular. Y es la religiosidad popular, en gran medida, la que ha permitido, en muchas personas, el tránsito de la era de cristiandad a la era secular, manteniendo, con acomodaciones, sus vivencias religiosas.

6. Insisto en ello. Ciertamente, en muchos casos hay una colusión entre tradición popular (fiestas locales, santos locales, tradiciones de siglos...) y sentimiento religioso, pero la fe o está incardinada en una cultura, o está impostada, cuando no impuesta por otra cultura o por una utilización del sentimiento religiosos en la propia cultura. La historia no muy lejana a la nuestra nos sirve más de un ejemplo.

7. Creo que habría que darse una vuelta por la inteligencia emocional y lo que hace décadas apuntaba el olvidado Xabier Zubiri sobre la inteligencia sentiente. Creo que serviría de puente entre el riesgo de rutinización del día del Señor y los riesgos de desbordamiento para-religioso de algunas manifestaciones de la religiosidad popular, de la piedad popular. 


\section{AMODO DE CONCLUSIÓN}

-En la actualidad, es más fácil saltarse la misa dominical que tal o cual procesión, tal o cual manifestación de piedad popular, que no tiene la periodicidad semanal de la misa dominical.

-Creo que la práctica de la misa dominical tal y como la hemos conocido, no volverá. No se confunda esto, sin embargo, con la labor que pueda realizar una parroquia como atención espiritual (u otra) a los fieles. Particularmente en momentos difíciles, como enfermedades, divorcios y separaciones, fallecimientos de seres queridos. Pero también en la animación y el acompañamiento de los fieles en su itinerario personal, tanto religioso como secular.

-Creo que en las parroquias hay que potenciar determinados momentos fuertes del calendario religioso, con misas muy bien preparadas y con información real a los feligreses (no basta un anuncio al final de la eucaristía del domingo, casi vacía en muchos lugares): Navidad, Semana Santa (sin que tenga que ser necesariamente -ni exclusivamente- el Triduo Pascual), que puede concretarse y concentrarse en otro domingo; Todos los santos, Pentecostés, advocación de esta o aquella Virgen, y por supuesto las festividades locales. La organización del tiempo civil, en la era secular, hace mucho que no va paralela al año litúrgico.

-Es más fácil asegurar actos puntuales en fechas concretas (Semana Santa, peregrinación diocesana, una marcha por un motivo determinado, etc.) que asegurar en todas las parroquias de España una celebración cuidada todos los domingos. La ausencia de nuevas vocaciones no es ajena a esta afirmación, pero no es, en absoluto, suficiente para explicarla. Me remito, en esta cuestión, a la dimensión teológica en las reflexiones del cardenal Kasper en el documento Munus santificandi que presento en el tercer excurso de este texto.

-Por último, sugiero que en las parroquias se preste una atención especial a la preparación de determinados actos de piedad popular. Un ejemplo entre otros muchos: una peregrinación, incluso individual, no reglamentada por la parroquia o por la diócesis, puede tener un ámbito de preparación en la propia parroquia. Lo mismo diría de una festividad local con su procesión u otra manifestación festivo-religiosa. Lo mismo diría del Camino de Santiago. Esta preparación no tiene por qué hacerla el cura. Pueden ser laicos preparados, estar abierta a no creyentes y con una publicitación más allá de la misa dominical. Quizá ya se hace y esta observación sea innecesaria. ¡Ojalá! 


\section{EXCURSUS}

\section{Peregrinaciones a Lourdes desde mi diócesis de San Sebastián}

Un amigo médico, que fue mi traumatólogo hasta que se jubiló, creyente, que durante muchos años acompañó a la peregrinación de mi diócesis de San Sebastián a Lourdes, me envía, a mi demanda, unas revistas referidas a Lourdes. Una de ellas, en francés, de abril de 2015, es el Boletín Oficial de la Asociación Médica Internacional Notre-Dame de Lourdes, que es el órgano oficial para las «constataciones medicas». El mismo Boletín, esta vez en castellano, de abril de 2004, revistas donde el rigor científico se alía con la piedad marial.

Pero también me manda tres ejemplares de la revista que edita la «Hospitalidad nuestra Señora de Lourdes de San Sebastián», que se define así en su web: «La Hospitalidad de Lourdes de Gipuzkoa es una asociación pública al servicio de los enfermos y disminuidos que integran la Peregrinación a Lourdes». Yo no pertenezco a ella, aunque sé de su existencia porque están, a veces, en la puerta de la iglesia en la cuestación por Lourdes y, sobre todo, porque tengo amigos que a ella pertenecen. En la revista, además de informaciones sobre la peregrinación y el santuario, reflexiones de índole religioso, encuentro muchos testimonios de personas que han participado como médicos, enfermeros, acompañantes, de ambos sexos, así como sacerdotes y religiosos.

Muchos testimonios, en gran parte por su sencillez y espontaneidad, son no solamente conmovedores, sino que nos mueven a reflexión.

En este excursus recojo unos pocos ejemplos. Un hombre, ya de edad avanzada, apunta que «nos embarcó en esta organización aita Txiki (literalmente, el padre Pequeño, un sacerdote o religioso, no lo sé) el año 1972» y cómo participó con su mujer en la creación de la hospitalidad en Santander.

Jose Luis Gorostidi, «Txolis», un cura entrañable que debe estar más cerca de los 90 que de los 80 , amigo próximo de mi mujer y mío, dice que «en 1954, (...) en aquellos años no había hospitalarios como ahora, nos llevaban a los seminaristas del último curso a Lourdes para hacer los trabajos de los hospitalarios», y desgrana en cuatro páginas algunas de sus experiencias como hospitalario.

Experiencia que también podemos leer en otro sacerdote, cuyo primer contacto, teniendo 23 años de edad, con la Hospitalidad la tuvo el año 1958 y que acabó siendo Consiliario de la Hospitalidad, misionero en Angola etc.

Traigo aquí el testimonio de una mujer en el que podemos leer que «empecé a ir a Lourdes el año 59. Íbamos con el obispo Font y Andreu (por cierto, el primer obispo de San Sebastián). Yo era la única enfermera titulada». 
Las anécdotas de cómo tenían que soltar las ventanillas de los trenes franceses (en Hendaia o en Lourdes), para quitar el cristal con un destornillador y poder pasar las camillas con los enfermos, nos hacen ver las reflexiones arriba apuntadas del actual obispo de Lourdes y las de los responsables del santuario cuando se preocupan de la dificultad del transporte de enfermos en tren. Yo diría la imposibilidad, pues hoy los trenes (como los autobuses modernos) son espacios cerrados que, entre otras cosas, no se ventilan nunca. Imposible introducir un enfermo en ellos.

Ahora que leo en sesudos trabajos socio-religiosos poner en valor la idea de la hospitalidad, como una nota que subrayar en el catolicismo en estos tiempos de crisis de todo, invito a que se lean estos testimonios (seguro que hay otros, tan valiosos en otras muchas diócesis) donde la hospitalidad era la razón de ser de estas personas. Hospitalidad llevada a la práctica, no solamente reflexionada y sugerida.

Mi amigo traumatólogo, a mi pregunta, me dice que cree que, en la actualidad, hay menos gente en las peregrinaciones diocesanas de Guipúzcoa a Lourdes, aunque también apunta a los que van por su cuenta. Con lo que la diócesis de San Sebastián no es excepción en el descenso de peregrinaciones organizadas. Además, en los boletines que me envía, de los años 2016, 2017 y 2018, veo poca gente joven en las fotos de las revistas. Añado, sin embargo, que mi amigo traumatólogo, que es también miembro del equipo médico que analiza las demandas anuales de enfermos que solicitan acudir a Lourdes, asegura que el año actual 2019 la demanda ha sido bastante superior a la oferta de plazas hospitalarias disponibles. Me señala, para concluir su correo, que «la visita a la Virgen de Lourdes, como médico de la peregrinación, me ha sido siempre profundamente gratificante. Acompañar a los enfermos, tirar de las camillas o sillas de ruedas (...) escuchar, dialogar, rezar con ellos... Compartir tiempo y descanso (y cervezas) con otros médicos (muchos extranjeros)». Una experiencia religiosa.

\section{Las peregrinaciones programadas en la diócesis de San Sebastián para el curso 2019-2020}

En mi propia diócesis de San Sebastián, consultada su web el 18 de julio de 2019, para este texto, puedo leer las siguientes peregrinaciones programadas para el curso 2019-2020:

-Peregrinación a Fátima: 20-24 octubre 2019.

-Javierada: 14 marzo 2020.

-Marcha a Aránzazu: 4 abril 2020.

-Marcha a San Ignacio: 25 abril 2020. 
-Marcha a Itziar: 3 mayo 2020.

-Peregrinación diocesana de enfermos a Lourdes: 21-25 mayo 2020.

-Peregrinación a Roma: octubre 2020.

\section{Reflexiones del cardenal Kasper en el documento "Munus santificandi»}

El cardenal Walter Kasper publicó el 31 de julio de 2019 una breve, pero muy enjundiosa, reflexión con motivo del Sínodo de la Amazonia, de la que he extraído algunas de sus ideas centrales, pues insiste en la importancia capital de la eucaristía dominical y sugiere algunas decisiones que adoptar, pensando precisamente en la dificultad práctica de la celebración de la misa dominical en la Amazonia de nuestros días. El documento completo puede consultarse en https://redamazonica.org/2019/07/munus-santificandi-ministros-en-las-comunidades-indigenas-y-el-derecho-de-acceso-a-la-eucaristia.

\section{Preguntas del cardenal Kasper}

-Tres preguntas en el punto "La Eucaristía dominical, santificación del cosmos y de la vida». Con la santificación del séptimo día, Dios dio un orden y un ritmo al tiempo que está inscrito en la misma realidad y, por tanto, se volvió un derecho humano, basado en su propia naturaleza. A esta altura brota mi primera pregunta: ¿cómo podemos no conceder este derecho de criaturas a los pueblos de la Amazonia? ¿Cómo podemos negarles la celebración de la Eucaristía con formas y canciones apropiadas a su cultura?

Los fieles deben participar en la Misa todos los domingos y festivos. (...) Tal mandamiento, bajo la amenaza de la pérdida de la vida eterna, no solo puede ser un mandamiento de la Iglesia, sino que necesita de fundamento en el mandamiento divino. Así que me hago una tercera pregunta: ¿cómo hace una entera iglesia local, como la de la Amazonia, para ser una iglesia en la tradición apostólica sin la regular celebración eucarística dominical?

-En el punto «La Eucaristía en la economía de la salvación». Permítanme terminar estas reflexiones con otra pregunta. Si sin participación en la Eucaristía falta algo esencial en el ser iglesia y si sin comer a la mesa eucarística la comunidad fraterna y la unidad de la Iglesia se debilitan, se desmoronan y corren el peligro de disolverse, la cuestión es: las comunidades cristianas ¿cómo pueden ser Iglesia en sentido pleno de la palabra si no participan regularmente en la celebración eucarística? Sin la Eucaristía, ¿no les falta algo, no les falta el centro, no carecen de lo esencial del ser Iglesia? ¿Cómo se les puede negar entonces el derecho a la Eucaristía? 
-En el punto «¿Qué significa derecho a la Eucaristía?». Todos los fieles han recibido el Espíritu en el Bautismo y la Confirmación; todos constituyen el pueblo santo de Dios. Todo el pueblo de Dios, debido al sensus fidei, goza de infalibilidad in credendo y participa en la función profética de Cristo.

Para conocer y comprender la auto-entrega de Cristo, que es su auto-comunicación en el Espíritu a la Iglesia, se necesita sentire Ecclesiam, vivir la Iglesia y vivir en la Iglesia, que en ocasiones puede ser también un sufrir con la Iglesia. No hay Magisterio sin compartir la fe vivida del pueblo de Dios. La introducción del Espíritu en toda la verdad se da caminando juntos en la fe (Papa Francisco). Esto es el sentido de un sínodo. El término griego synodos significa estar juntos en el camino, ser synodoi, es decir, compañeros en el camino y escuchar juntos lo que el Espíritu dice a las iglesias.

\section{Tres conclusiones concretas}

1. Según todo lo que hemos dicho, existe tal derecho (a la Eucaristía dominical) no solo subjetivo, no solo por una reivindicación individual, sino por un derecho comunitario que deriva de la esencia de la Eucaristía y de su lugar en la economía de la salvación. Puede haber circunstancias extraordinarias, como situaciones de persecución, guerra, desastres naturales, accidentes graves, etc. que hacen imposible la celebración eucarística, pero si en circunstancias normales las comunidades alrededor tienen espacios y distancias que permiten solo una o dos veces al año tener acceso a la Eucaristía, carecen de algo esencial para ser Iglesia. Estas comunidades tienen el derecho de que el obispo haga todo lo posible de su parte para cambiar esta situación.

2. La razón principal de esta situación es la escasez de sacerdotes y candidatos al sacerdocio en la Amazonia. Hay muchas razones para esta escasez. (...) El celibato puede ayudar y facilitar el ministerio pastoral, pero no debe llevarnos a una Iglesia de visitas en lugar de una Iglesia que permanece, acompaña, está presente y comparte la vida cotidiana y sirve para santificarla. Por lo tanto, se debe escuchar lo que el Espíritu sugiere a las Iglesias, reflexionar y meditar a conciencia si en esta situación es deseable con el consentimiento del Papa ordenar al sacerdocio hombres de fe probada que viven la vida matrimonial y de familia (llamados viri probati). De la misma manera, es necesario identificar qué tipo de ministerio oficial se puede otorgar a las mujeres teniendo en cuenta el importante papel que ya desempeñan en las comunidades eclesiales indígenas.

3. Los dones eucarísticos son «fruto de la tierra y del trabajo del hombre», es decir, fruto de la cultura que el Creador ha confiado al hombre. Así, 
la Eucaristía se entreteje con toda la naturaleza, el cosmos y la cultura indígena. Por lo tanto, se pide con toda legitimidad una inculturación de la celebración sacramental y, por consiguiente, también de los celebrantes que viven en ese entorno natural y en la cultura indígena, es decir, que al menos estén dispuestos a sumergirse, entender, estimar y amar esa cultura.

\section{Reflexiones finales}

Aquí no puedo profundizar en la teología de la inculturación. Pero vale la pena recordar que la inculturación no es solo una aculturación, es decir, una adaptación que introduce algunos elementos de la cultura indígena en la liturgia cristiana. La inculturación va más allá y es más profunda; implica una penetración interior y una transformación de la cultura desde dentro. En cierto sentido, podemos hablar de una transformación de la cultura a través de un proceso pascual.

A la pregunta de cómo debe llevarse a cabo concretamente una inculturación de este tipo, no puede responderse en abstracto. En la práctica, las respuestas concretas no se pueden deducir teóricamente de los principios generales, sino solo a través de la virtud de la sabiduría y la prudencia, iluminadas por el amor. Incluso Dios gobierna el mundo no como una máquina que se carga mecánicamente, sino con sabiduría y providencia. La prudencia y la sabiduría son las virtudes fundamentales de cualquier gobierno, sea civil o eclesiástico. Por lo tanto, concluyo con el deseo de que Dios bendiga con esta prudencia y con esta sabiduría, junto con el valor necesario de la parresía bíblica, el sínodo inminente para el bien de los pueblos de la Amazonia y tal vez profético para la Iglesia universal. 